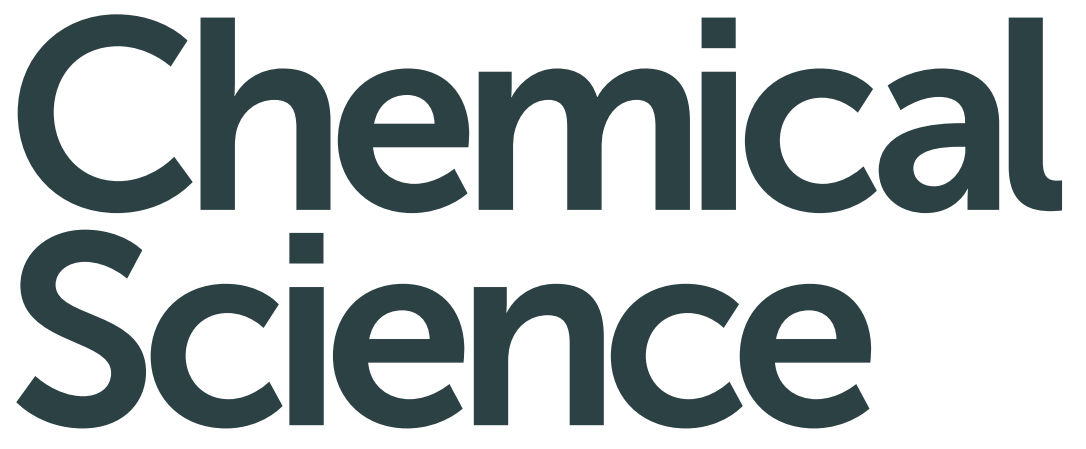

www.rsc.org/chemicalscience

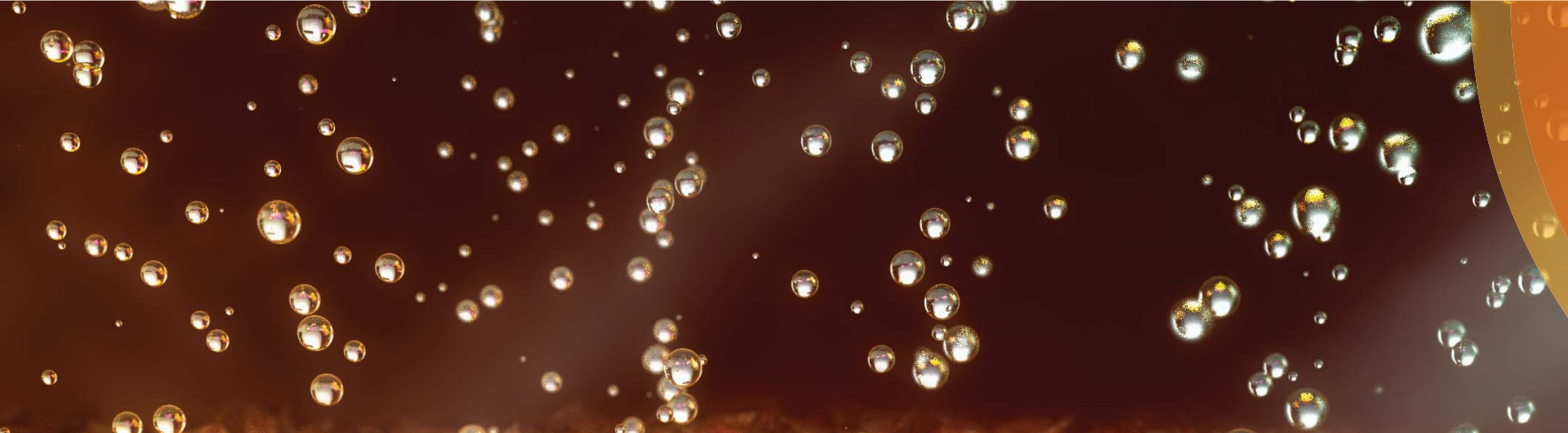

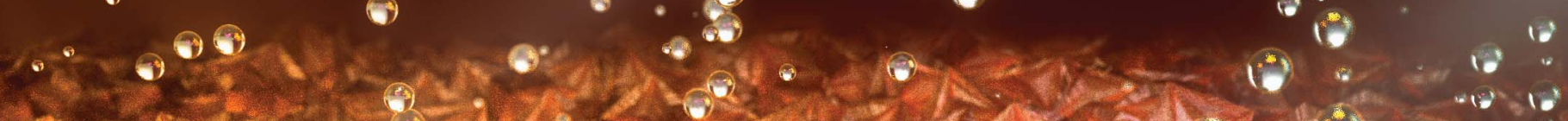

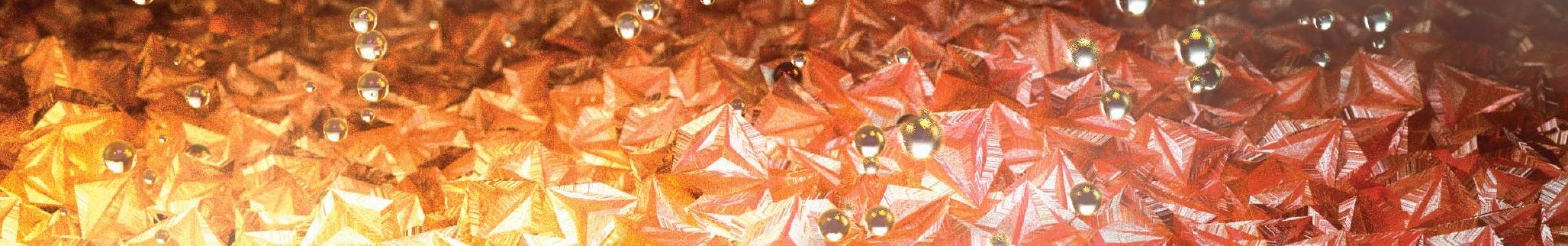

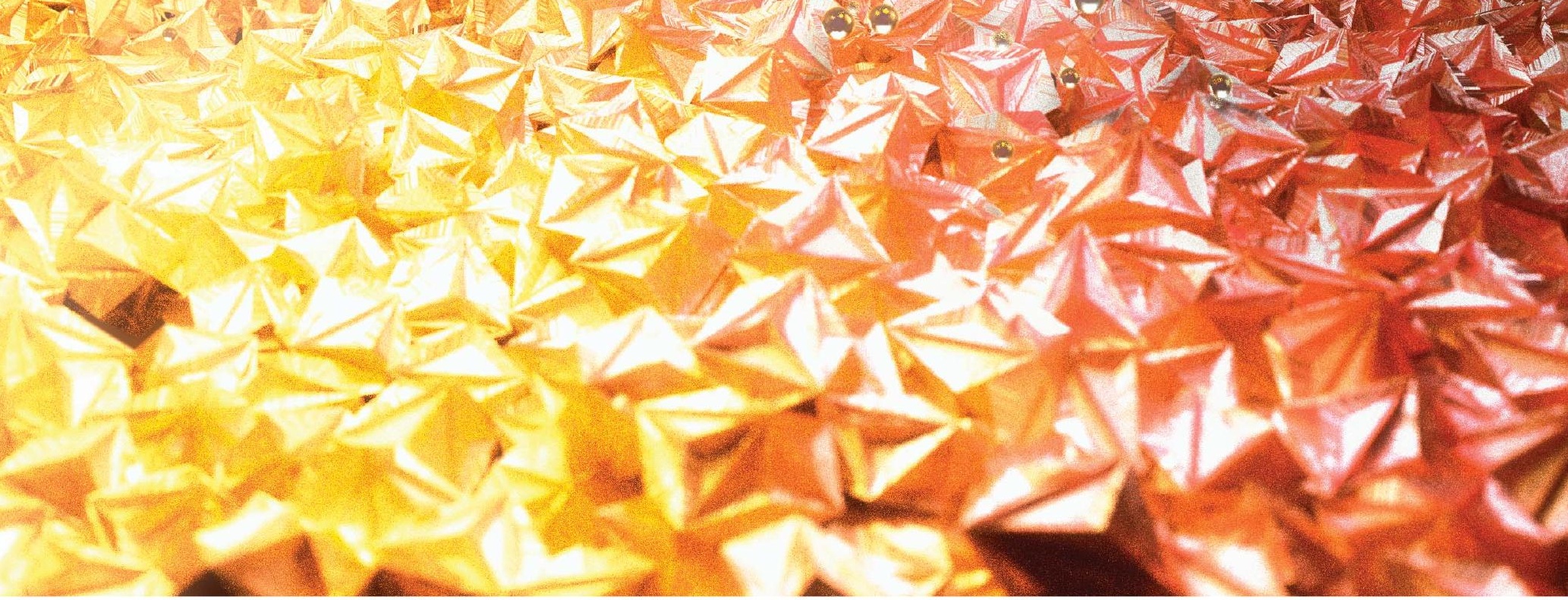

ISSN 2041-6539

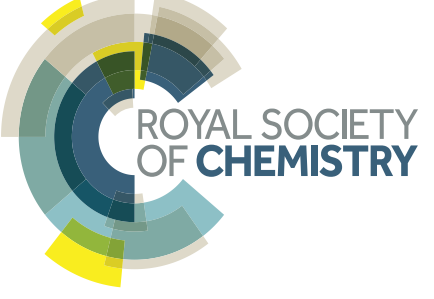

EDGE ARTICLE

Claire J. Carmalt et al.

Bismuth oxyhalides: synthesis, structure and photoelectrochemical activity 


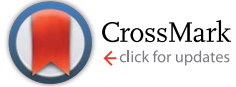

Cite this: Chem. Sci., 2016, 7, 4832

Received 26th January 2016 Accepted 5th March 2016

DOI: $10.1039 / \mathrm{c} 6 \mathrm{sc} 00389 \mathrm{c}$

www.rsc.org/chemicalscience

\section{Bismuth oxyhalides: synthesis, structure and photoelectrochemical activity $\dagger$}

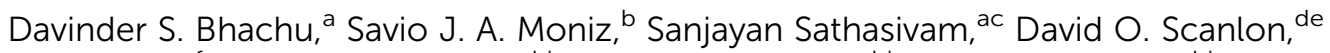 \\ Aron Walsh, ${ }^{\text {fg }}$ Salem M. Bawaked, ${ }^{\text {hi }}$ Mohamed Mokhtar, ${ }^{\text {hi }}$ Abdullah Y. Obaid, ${ }^{\text {hi }}$ \\ Ivan P. Parkin, ${ }^{a}$ Junwang Tang $^{\mathrm{b}}$ and Claire J. Carmalt ${ }^{\star a}$
}

\section{Introduction}

Photoelectrochemical (PEC) water splitting was known as early as 1969 from work carried out by Fujishima and Honda on n-type rutile $\mathrm{TiO}_{2}$ single crystals. ${ }^{\mathbf{1 , 2}}$ This finding laid the foundations for the development of materials that harvest solar energy for photocatalytic purification and solar energy conversion. The PEC process proceeds when a semiconducting material absorbs light that is equal or above the energy of its optical bandgap. This then results in electrons or holes that are transported to surface sites where redox reactions can occur. Additionally, the carriers must have sufficient chemical

\footnotetext{
${ }^{a}$ Materials Chemistry Centre, Department of Chemistry, University College London, 20 Gordon Street, London WC1H OAJ, UK.E-mail: c.j.carmalt@ucl.ac.uk

${ }^{b}$ Department of Chemical Engineering, University College London, Torrington Place, London WC1E 7JE, UK

${ }^{c}$ Bio Nano Consulting Ltd, The Gridiron Building, One Pancras Square, London N1C $4 A G, U K$

${ }^{d}$ University College London, Kathleen Lonsdale Materials Chemistry, Department of Chemistry, 20 Gordon Street, London WC1H OAJ, UK

${ }^{e}$ Diamond Light Source Ltd., Diamond House, Harwell Science and Innovation Campus, Didcot, Oxfordshire OX11 ODE, UK

${ }^{f}$ Centre for Sustainable Chemical Technologies, Department of Chemistry, University of Bath, Bath, BA2 7AY, UK

${ }^{g}$ Global $E^{3}$ Institute, Department of Materials Science and Engineering, Yonsei University, Seoul 120-749, Korea

${ }^{h}$ Chemistry Department, Faculty of Science, King Abdulaziz University, Saudi Arabia ${ }^{i}$ Surface Chemistry and Catalytic Studies Group, King Abdulaziz University, Saudi Arabia
}

$\dagger$ Electronic supplementary information (ESI) available. See DOI: $10.1039 / \mathrm{c} 6 \mathrm{sc} 00389 \mathrm{c}$ potential to drive water oxidation and reduction, as determined by the absolute band energies. ${ }^{3-5} \mathrm{TiO}_{2}$ is the most studied material for this application as it not only meets the aforementioned criteria but is also highly photoactive. ${ }^{6-8}$ However, the optical bandgap of $\mathrm{TiO}_{2}$ at around $3.0 \mathrm{eV}$ lies in the ultraviolet (UV) portion of the solar spectrum, which severely limits the maximum power conversion. ${ }^{9-11}$ As a result, PEC research of late has been heavily driven into finding visible light active materials suitable for photoelectrodes. ${ }^{\mathbf{1 2 - 1 4}}$

Traditional methods to visible light active materials have involved modifying wide gap semiconductors such as $\mathrm{TiO}_{2}$ and $\mathrm{ZnO}$ through doping, alloying, junction formation or sensitization in order to drive the bandgap into the visible region with varying degrees of success. ${ }^{\mathbf{1 1 , 1 2 , 1 4 - 1 9}}$ The second approach has been to use well-known solar absorber materials, such as $\mathrm{Si}$, $\mathrm{GaP}$ and GaAs that have much lower optical band gaps than $\mathrm{TiO}_{2}{ }^{13}$ For example III-V semiconductor materials such as $\mathrm{GaInP}_{2}$ and $\mathrm{n}-\mathrm{p}$ junctions of GaAs coupled to a Pt counter electrode have resulted in light conversion efficiencies of $12.4 \% .^{13}$ These materials however are quite unstable in aqueous conditions. Recent work by the Lewis group showed that unstable photoanodes such as $\mathrm{Si}, \mathrm{GaP}$ and GaAs could be markedly improved in terms of stability and hole conduction by protecting the photoelectrodes with $\mathrm{TiO}_{2}$ layers grown by atomic layer deposition (ALD) and adding a surface electrocatalyst. ${ }^{13}$ More recently, solution processed tandem solar cells of $\mathrm{CH}_{3} \mathrm{NH}_{3} \mathrm{PbI}_{3}$ coupled to a NiFe layered double hydroxide catalyst demonstrated a solar-to-hydrogen efficiency of $\sim 12.3 \% .^{20}$ Material instability under working conditions however was again a significant issue. The third strategy 
involves developing new functional systems. These are materials that have not been conventionally used as photoelectrodes and range from simple oxides, sulphides, ${ }^{21}$ complex oxides and more recently metal-free materials such as graphitic carbonnitride.$^{22-25}$ Bismuth oxyhalides, $\mathrm{BiOX}(\mathrm{X}=\mathrm{Cl}, \mathrm{Br}, \mathrm{I})$ are a class of V-VI-VII ternary semiconductor materials. ${ }^{26-28}$ These materials all crystallise in a tetragonal matlockite structure, ${ }^{29,30}$ which is a layered structure made up of $[\mathrm{X}-\mathrm{Bi}-\mathrm{O}-\mathrm{Bi}-\mathrm{X}]$ slabs stacked together by van der Waals interactions, as shown in Fig. 1. In this $[\mathrm{X}-\mathrm{Bi}-\mathrm{O}-\mathrm{Bi}-\mathrm{X}]$ motif, each bismuth centre is surrounded by four oxygen atoms and four halogen atoms, giving rise to an asymmetric decahedral symmetry. The combination of strong intralayer covalent bonding coupled with interlayer van der Waals attractions makes these materials interesting for anisotropic structural, electrical, optical and mechanical properties..$^{28}$ Traditionally, bismuth oxyhalides have been investigated as catalysts, ferroelectric materials, storage materials, and pigments..$^{31}$ More recently however, these materials have been tested for a wide range of applications from photocatalytic waste water and indoor-gas purification, water splitting, organic synthesis, and selective oxidation of alcohols. ${ }^{31-34}$ These materials have shown some promise in the photocatalytic degradation of organic dyes, but very little has been reported on their PEC properties..$^{27,31,35-37}$ Their potential arises from the open crystalline structure of the material coupled with an indirect band gap that reduces the probability for electron-hole recombination. ${ }^{38}$ In addition, the crystal structure also results in internal electric fields perpendicular to the $[\mathrm{X}-\mathrm{Bi}-\mathrm{O}-\mathrm{Bi}-\mathrm{X}]$ slabs. ${ }^{39}$ This can potentially facilitate efficient charge separation along the [001] direction, thus further suppressing recombination. ${ }^{38}$

In the present study, a series of $\mathrm{BiOX}(\mathrm{X}=\mathrm{Cl}, \mathrm{Br}, \mathrm{I})$ films were synthesised, for the first time, using aerosol assisted chemical vapour deposition (AACVD). The films were characterised structurally using a combination of standard laboratory techniques and compared to density functional theory (DFT)

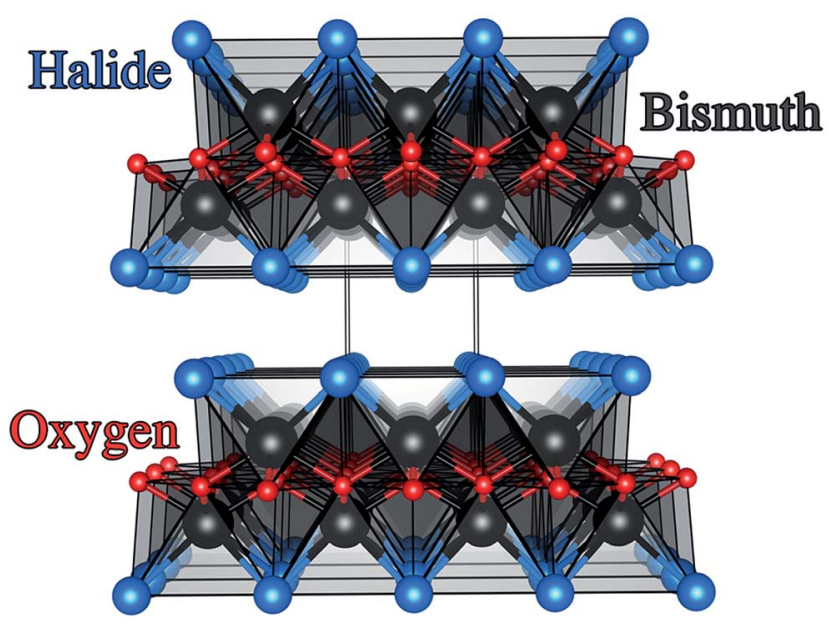

Fig. 1 Crystal structure of the BiOX systems (space group $P 4 / \mathrm{nmm}$, $\mathrm{D}_{4 \mathrm{~h}}$ symmetry) with stoichiometric $\mathrm{X}-\mathrm{Bi}-\mathrm{O}-\mathrm{Bi}-\mathrm{X}$ bi-layers stacked along the $c$ axis. Bismuth, oxygen and halide ions are denoted by black, red and blue spheres, respectively. calculations, which provides insights into the electronic structure of these materials. More importantly, and to gain a complete understanding of the photophysical properties of the as-deposited BiOX films, their photoelectrochemical response was analysed under $100 \mathrm{~mW} \mathrm{~cm}{ }^{-2}$ illumination in $0.5 \mathrm{M} \mathrm{Na}_{2} \mathrm{SO}_{4}$ electrolyte. All films showed photoactivity, with the BiOBr sample showing the highest photocurrent ever reported for that system without the use of a sacrificial electron donor. The BiOBr film even displayed photocurrents three times higher than that recorded for a BiOBr-reduced graphene composite electrode that was tested under similar conditions by Li $e t$ al. ${ }^{40}$ Furthermore, the BiOBr film also showed the best photostability, with only limited photocorrosion after one hour of testing, compared to the BiOCl and BiOI deposited by AACVD.

\section{Experimental}

\section{Synthetic procedure}

Depositions were carried out under air. Precursors were placed in a glass bubbler and an aerosol mist was created using a piezoelectric device (Fig. 2). All chemicals were procured from Aldrich and were used as received.

$\mathrm{BiX}_{3}(\mathrm{X}=\mathrm{Cl}, \mathrm{Br}, \mathrm{I})(1 \mathrm{mmol})$ was dissolved in $N, N$-dimethylformamide $(25 \mathrm{ml})$. The resulting solution was stirred for 30 minutes and then atomised. The precursor flow was kept at $11 \mathrm{~min}^{-1}$. The glass substrate was FTO glass, NSG TEC ${ }^{\mathrm{TM}} 15$, $15 \mathrm{~cm} \times 4 \mathrm{~cm} \times 0.3 \mathrm{~cm}$. A top plate was suspended $0.5 \mathrm{~cm}$ above the glass substrate to ensure laminar flow. The substrate was maintained at a temperature of $300^{\circ} \mathrm{C}$ for a deposition time of 60 minutes. After the deposition the bubblers were closed and the substrates were cooled under a flow of air. The glass substrate was allowed to cool with the graphite block to less than $100{ }^{\circ} \mathrm{C}$ before it was removed. Coated substrates were handled and stored in air. The coated glass substrate was cut into $c a .1 \mathrm{~cm} \times 1 \mathrm{~cm}$ squares for subsequent analysis.

\section{Film characterisation}

Powder X-ray diffraction (PXRD) patterns were measured in a modified Bruker-Axs D8 diffractometer with parallel beam optics and a PSD LynxEye silicon strip detector. This instrument

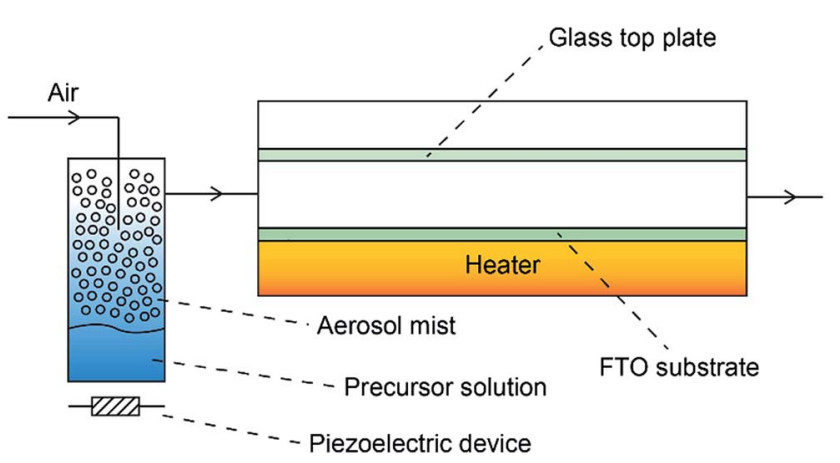

Fig. 2 Schematic of the AACVD used for the deposition of BiOX films on FTO substrates. The aerosol mist of the precursor solution that was generated by a piezoelectric device was carried over the heated FTO substrate in the CVD reaction chamber using air. 
uses an unmonochromated $\mathrm{Cu} \mathrm{K} \alpha$ source operated at $40 \mathrm{kV}$ with a $30 \mathrm{~mA}$ emission current. The incident beam angle was set at $1^{\circ}$ and the angular range of the patterns collected was $8^{\circ}<2 \theta<66^{\circ}$ with a step size of $0.05^{\circ}$ counted at $0.5 \mathrm{~s}$ per step. Scanning electron microscopy (SEM) was performed to determine surface morphology and film thickness using a JEOL JSM-6301F Field Emission SEM at an accelerating voltage of $5 \mathrm{keV}$. Optical spectra were obtained using a Perkin Elmer Fourier transform Lambda 950 spectrometer over a wavelength range of $300 \mathrm{~nm}$ to $1100 \mathrm{~nm}(4.1 \mathrm{eV}$ to $1.1 \mathrm{eV})$. This range embraces the ultraviolet (UV), visible and near infrared (NIR) regions. The spectra were referenced against an air background. X-ray photoelectron spectroscopy (XPS) was performed in a Thermo Scientific K-alpha photoelectron spectrometer using monochromatic $\mathrm{Al}-\mathrm{K} \alpha$ radiation. Survey scans were collected in the range 0$1100 \mathrm{eV}$ (binding energy) at a pass energy of $160 \mathrm{eV}$. Higher resolution scans were recorded for the main core lines at a pass energy of $20 \mathrm{eV}$. Valence band spectra were also recorded. Peak positions were calibrated to carbon and plotted using CasaXPS software.

\section{Photoelectrochemical testing}

The PEC measurements were conducted in a three-electrode cell equipped with a quartz window and potentiostat (Ivium technology). The as-prepared films were used as the working electrodes. Pt mesh and $\mathrm{Ag} / \mathrm{AgCl}(3 \mathrm{M} \mathrm{KCl})$ were used as counter electrodes and reference electrodes, respectively. The scan speed was $20 \mathrm{mV} \mathrm{s}^{-1}$ between -0.5 and $1.5 \mathrm{~V}$ ( $v s$. $\left.\mathrm{Ag} / \mathrm{AgCl}\right)$. The electrolyte was $0.5 \mathrm{M} \mathrm{Na}_{2} \mathrm{SO}_{4}(\mathrm{pH}$ 6.5) aqueous solution, degassed with argon for $30 \mathrm{~min}$. A $150 \mathrm{~W}$ xenon lamp (Newport, USA) equipped with an AM 1.5 G filter was used to irradiate the electrodes from the front side and was calibrated to 1 sun illumination (100 $\mathrm{mW} \mathrm{cm}^{-2}$ ) using a photodiode. MottSchottky (impedance) plots were obtained at a frequency of 1 $\mathrm{kHz}$ in the dark with an AC amplitude of $5 \mathrm{mV}$. The flat band potential $\left(V_{\mathrm{fb}}\right)$ was determined by eqn (1):

$$
\frac{1}{C^{2}}=\frac{2}{\varepsilon_{0} \varepsilon_{\mathrm{r}} e N_{\mathrm{A}}}\left(V-V_{\mathrm{fb}}-\frac{k_{\mathrm{B}} T}{e}\right)
$$

here $N_{\mathrm{A}}$ is the carrier density, $\varepsilon_{0}$ is the permittivity in a vacuum, $\varepsilon_{\mathrm{r}}$ is the relative permittivity, $V$ is the applied potential, $T$ is the absolute temperature, $e$ corresponds to the electronic charge, and $k_{\mathrm{B}}$ is the Boltzmann constant. Hence a plot of $1 / C^{2} v s$. potential $(V)$ will yield a line, which when extrapolated to the $x$-axis, will correspond to the flat-band potential of the semiconductor. ${ }^{1}$ Potentials were referenced to the reversible hydrogen electrode (RHE) using the Nernst equation (eqn (2)):

$$
\begin{aligned}
E_{\mathrm{RHE}} & =E_{\mathrm{Ag} / \mathrm{AgCl}}^{0}+E_{\mathrm{Ag} / \mathrm{AgCl}}+0.059 \mathrm{pH}, E_{\mathrm{Ag} / \mathrm{AgCl}}^{0} \\
& =0.1976 \text { at } 25^{\circ} \mathrm{C}
\end{aligned}
$$

\section{Computational methods}

All electronic structure calculations were performed using the Vienna $A b$ initio Simulation Package (VASP), ${ }^{41-44}$ a periodic plane wave DFT code which includes interactions between the core and valence elections using the Project Augmented Wave (PAW) method..$^{45}$ Both the plane wave basis set and $k$-point sampling were checked for convergence, with a cutoff of $520 \mathrm{eV}$ and $k$-point grid of $\Gamma$-centred $6 \times 6 \times 2$, and for the unit cell of BiOX were found to be sufficient. Geometry optimization was performed using the Heyd-Scuseria-Ernzerhof (HSE06) hybrid DFT functional ${ }^{46}$ with the inclusion of Grimme's D3 correction, ${ }^{47}$ which deals with the inability of DFT to describe weak dispersion interactions. Relativistic spin orbit effects (SOC) were included for the band structure calculations, as materials containing heavy elements such as Bi and I are known to display large relativistic renormalization. ${ }^{48-50}$

\section{Results and discussion}

BiOX (where $\mathrm{X}=\mathrm{Cl}, \mathrm{Br}, \mathrm{I}$ ) films were deposited on FTO substrates from the AACVD reaction of $\mathrm{BiX}_{3}$ and $\mathrm{N}, \mathrm{N}$-dimethylformamide at $300{ }^{\circ} \mathrm{C}$. The films were uniform, showed excellent coverage across the FTO substrate and were well adhered, passing the Scotch ${ }^{\mathrm{TM}}$ tape test.

\section{XRD, SEM, optical and XPS characterization}

$\mathrm{X}$-ray diffraction patterns of the as-deposited films formed by AACVD (Fig. 3) confirmed the presence of BiOX $(\mathrm{X}=\mathrm{Cl}, \mathrm{Br}, \mathrm{I})$. All the films were phase pure and crystallised in the expected tetragonal matlockite structure. The BiOI films displayed pronounced (011) texture. This is in contrast to previous reports on spray deposited BiOI thin films displaying preferred (102) followed by (110) orientation. ${ }^{51}$ The BiOBr films exhibited (001) and (101) texture, whereas the BiOCl films showed mainly (101) and (110) texture. It has been noted before in the literature that this texture/faceted nature of the crystals may be beneficial in establishing internal electric fields aiding electron-hole charge separation in these materials. ${ }^{38}$

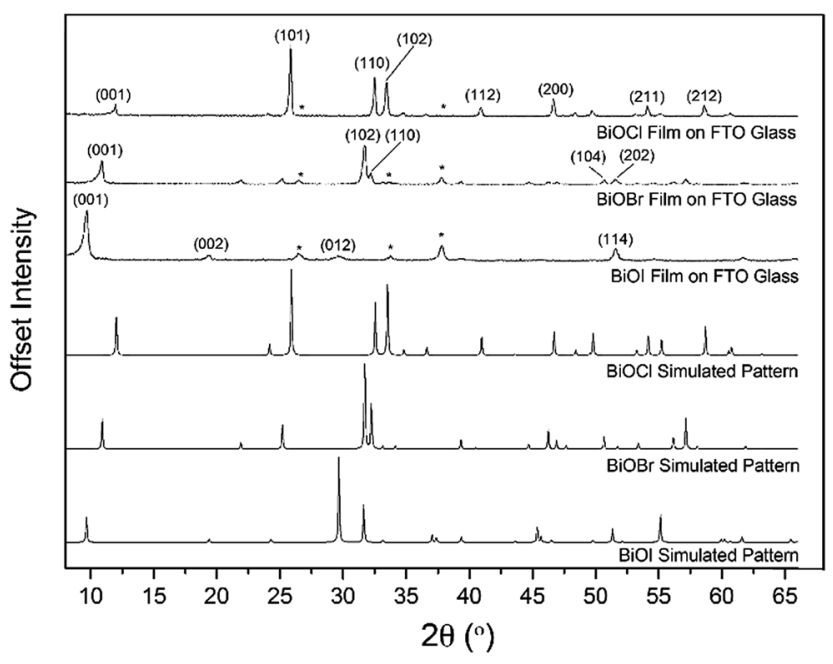

Fig. 3 PXRD of $\mathrm{BiOX}(\mathrm{X}=\mathrm{Cl}, \mathrm{Br}$, I) films deposited on FTO glass from the $A A C V D$ reaction of $\mathrm{BiX}_{3} / D M F$ in air at $300{ }^{\circ} \mathrm{C}$ along with simulated BiOX patterns. The asterisked peaks correspond to positions of reflections from the $\mathrm{F}: \mathrm{SnO}$ (FTO) substrate. 
The film microstructure was probed using SEM as shown in Fig. 4. BiOI and BiOCl films consist of a nanoplatelet morphology with the platelets (i.e. grains) ranging from 0.5$1 \mu \mathrm{m}$ (BiOI) and at $\sim 1 \mu \mathrm{m}$ (BiOCl) while having a thickness within the nano regime (50 and $250 \mathrm{~nm}$, respectively). The $\mathrm{BiOBr}$ sample however consists of clusters of crystallites contributing to the particles resembling nanoflowers. The clusters were around $1 \mu \mathrm{m}$ in diameter and appear to be composed of smaller crystallites. As mentioned before, the electronic properties of these materials are anisotropic and this faceted growth may help charge carrier mobility along certain facets. Optical spectra across the UV, visible and near IR regions were collected for the BiOX thin films and the absorbance data is plotted from $300 \mathrm{~nm}$ to $1100 \mathrm{~nm}$ in Fig. 5a. As shown, the absorption edge decreases in energy with halide anion going down group 17. Fig. $5 \mathrm{~b}$ shows the Tauc plot of $(\alpha h \nu)^{1 / 2}$ versus photon energy $(h \nu)$ for BiOX $(\mathrm{X}=\mathrm{Cl}, \mathrm{Br}, \mathrm{I})$. Note the use of the indirect Tauc relation. It can be seen that BiOCl exhibits the largest indirect bandgap of around $3.3 \mathrm{eV}$, within the $\mathrm{UV}$ region. For BiOBr however, the indirect bandgap red shifts to a value of $2.7 \mathrm{eV}$ (corresponding to $460 \mathrm{~nm}$ ). Moving to BiOI, the bandgap shifts further into the visible region with a value of around $1.8 \mathrm{eV}$ (690 nm light). These values are in excellent agreement with reported literature on these materials prepared by other routes. ${ }^{30,52,53}$

BiOX core level X-ray photoemission spectroscopy (XPS) was performed on all of the samples as shown in Fig. 6 to probe the surface composition. Fig. 6a shows the core level XPS for BiOCl. For clarity, only the metal and halide transitions are shown. The binding energy for the $\mathrm{Bi} 4 \mathrm{f}_{7 / 2}$ transition at $159.7 \mathrm{eV}$ clearly corresponds to $\mathrm{Bi}^{3+} \cdot{ }^{54,55}$ There is a minor metallic bismuth $\left(\mathrm{Bi}^{0}\right)$ component corresponding to a $\mathrm{Bi} 4 \mathrm{f}_{7 / 2}$ transition at a binding energy of $157.9 \mathrm{eV}$. The $\mathrm{Cl}^{-} 2 \mathrm{p}_{3 / 2}$ and $2 \mathrm{p}_{1 / 2}$ transitions were observed at binding energies of $198.4 \mathrm{eV}$ and $200 \mathrm{eV}$, respectively. This metallic bismuth component has been observed in many reports but is often not discussed. The nature of metallic bismuth could well be due to instability of the material under incident X-rays resulting in photoreduction to metallic bismuth. This has been observed before in bismuth based materials and also in similar compounds such as $\mathrm{CH}_{3} \mathrm{NH}_{3} \mathrm{PbI}_{3}$ where a metallic lead signal is found. ${ }^{56,57}$ Fig. $6 \mathrm{c}$ shows the core level XPS for BiOBr. The binding energy for the $\mathrm{Bi} 4 \mathrm{f}_{7 / 2}$ a)

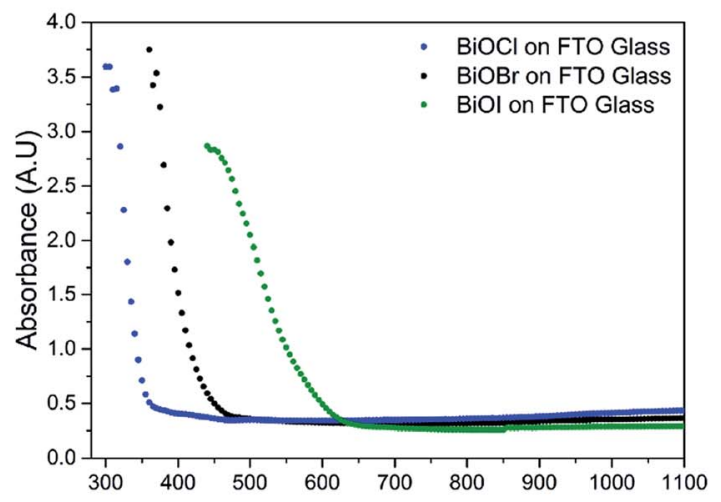

b)

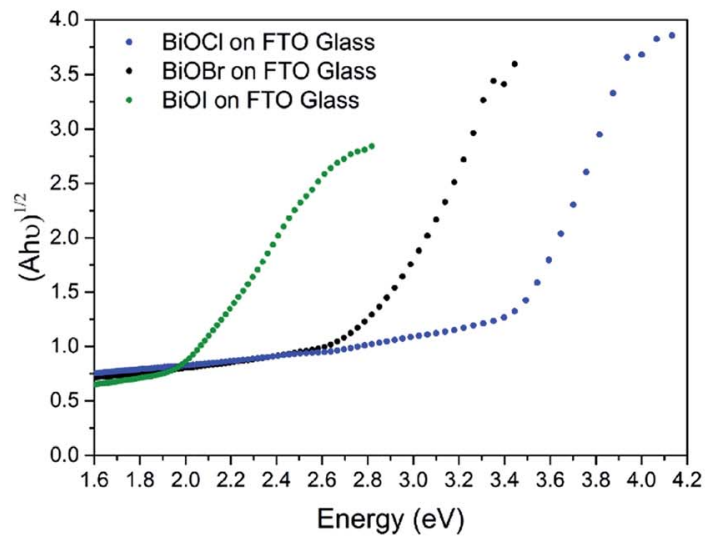

Fig. 5 (a) UV/vis spectra of $\mathrm{BiOX}(\mathrm{X}=\mathrm{Cl}, \mathrm{Br}, \mathrm{I})$ films deposited on FTO glass and (b) corresponding Tauc plots.

transition at $159.4 \mathrm{eV}$ clearly corresponds to $\mathrm{Bi}^{3+} .^{58}$ There also appears to be a minor metallic bismuth component in this sample but it is significantly reduced in comparison to the BiOCl film. Again, the least-squares fit is markedly improved with metallic bismuth components included in the model. The bromide peaks correspond to binding energies of $\mathrm{Br}^{-}$and agree well with literature values. ${ }^{58}$ Fig. 6e shows the core level XPS for BiOI. The binding energy for the $\mathrm{Bi} 4 \mathrm{f}_{7 / 2}$ transition at $159.2 \mathrm{eV}$ matchs with $\mathrm{Bi}$ in the $3+$ oxidation state. ${ }^{59}$ Similar to $\mathrm{BiOBr}$, the metallic bismuth component is less than in the case of BiOCl.

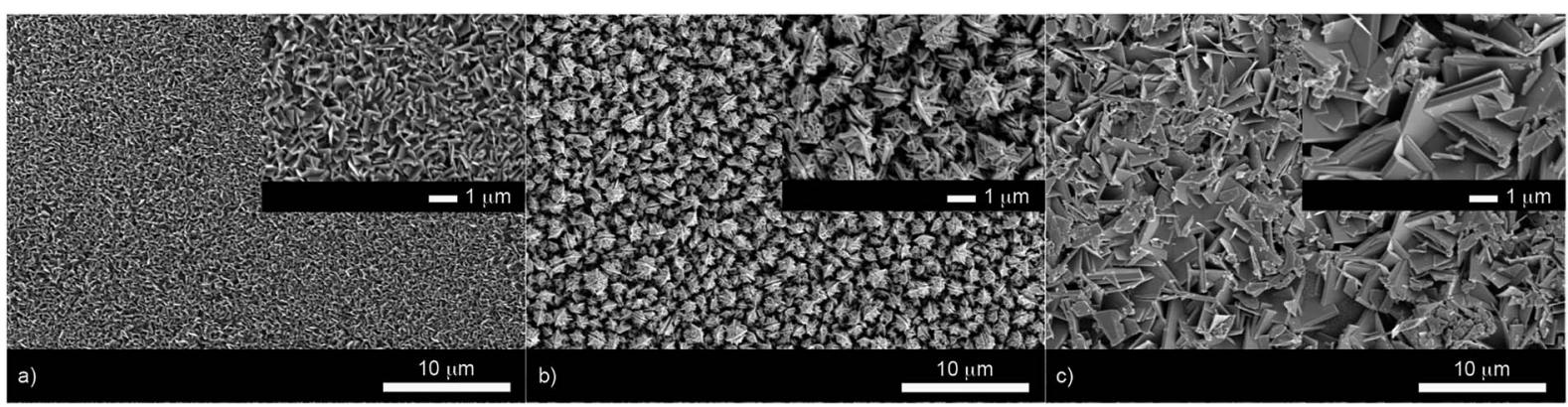

Fig. $4 \mathrm{SEM}$ images of (a) $\mathrm{BiOl}$, (b) $\mathrm{BiOBr}$ and (c) $\mathrm{BiOCl}$ thin films deposited on $\mathrm{FTO}$ glass from the $\mathrm{AACVD}$ reaction of $\mathrm{BiX} \mathrm{X}_{3} / \mathrm{DMF}$ in air at $300{ }^{\circ} \mathrm{C}$. Insets show a higher magnification image of the same area. 

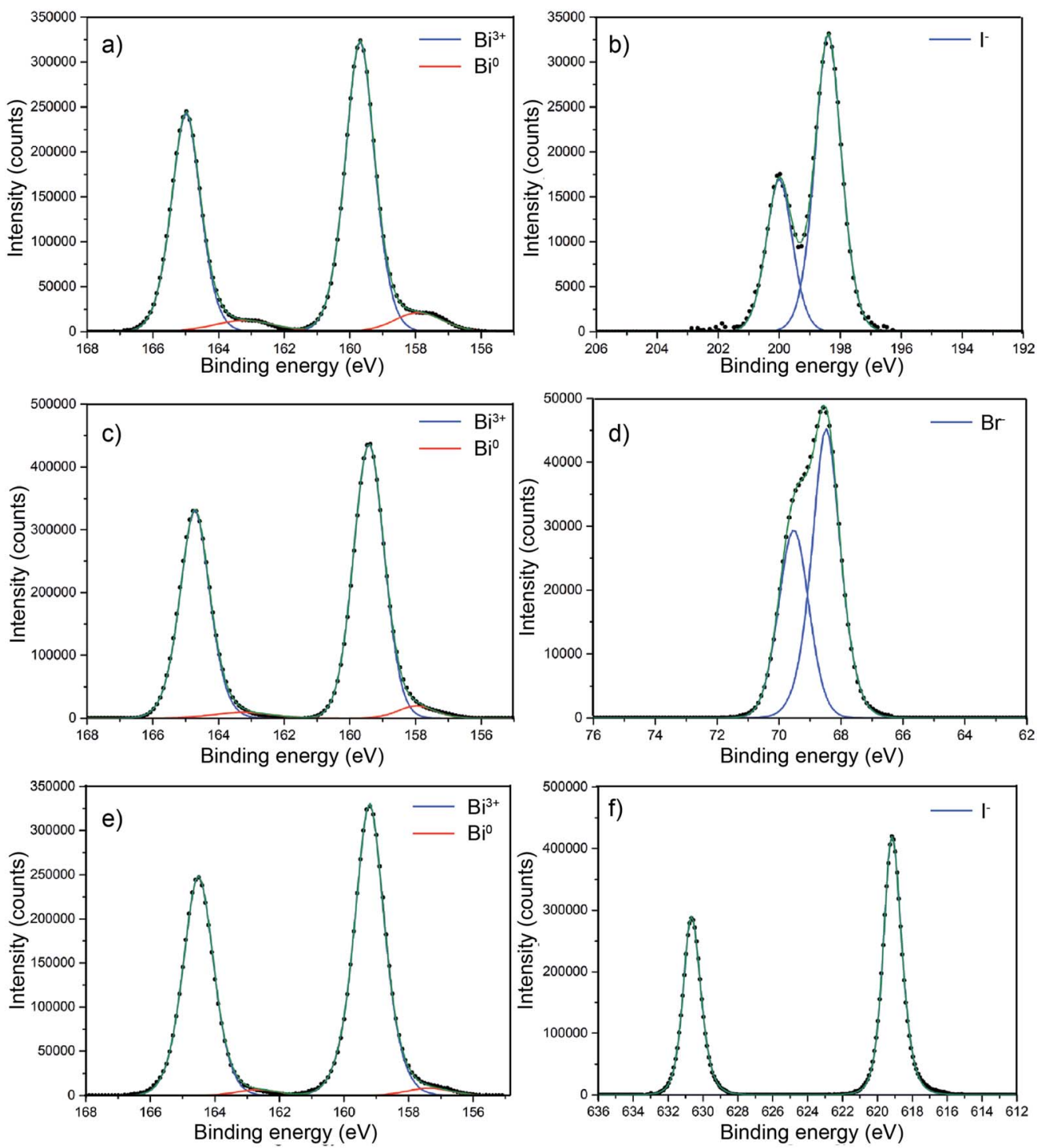

Fig. 6 Core level X-ray photoemission spectra of (a) BiOCl on $\mathrm{FTO}$ glass showing the $\mathrm{Bi}^{3+} 4 \mathrm{f}_{7 / 2}$ and $4 \mathrm{f}_{5 / 2}$ transitions, with a minor $\mathrm{Bi}^{\left({ }^{(0)}\right.}$ component at a lower binding energy. (b) $\mathrm{Cl}^{-} 2 \mathrm{p}_{3 / 2}$ and $2 \mathrm{p}_{1 / 2}$ transitions are also shown. (c) BiOBron FTO glass showing the $\mathrm{Bi}^{3+} 4 \mathrm{f}_{7 / 2}$ and $4 \mathrm{f}_{5 / 2}$ transitions with a minor $\mathrm{Bi}^{(0)}$ component at a lower binding energy, along with the corresponding $\mathrm{Br}^{-} 3 \mathrm{~d}_{5 / 2}$ and $3 \mathrm{~d}_{3 / 2}$ transitions (d). (e) BiOl on $\mathrm{FTO}$ glass showing the $\mathrm{Bi}^{3+} 4 \mathrm{f}_{7 / 2}$ and $4 \mathrm{f}_{5 / 2}$ transitions with a minor $\mathrm{Bi}^{(0)}$ component at a lower binding energy, with $\mathrm{I}^{-} 3 \mathrm{~d}_{5 / 2}$ and $3 \mathrm{~d}_{3 / 2}$ transitions (f).

The binding energy of the iodide transitions are consistent with the literature. ${ }^{59}$

\section{Electronic structure}

The valence band maximum for BiOX crystals is known to be comprised of $\mathrm{O} 2 \mathrm{p}$ orbitals and $\mathrm{X} n \mathrm{p}$ states $(n=3,4,5$ and $\mathrm{X}=$ $\mathrm{Cl}, \mathrm{Br}$ and $\mathrm{I}$, respectively). The conduction band minimum is mainly comprised of $\mathrm{Bi} 6 \mathrm{p}$ states. As X gets larger, the contribution of $\mathrm{X} n \mathrm{~s}$ states increases. This results in a narrowing of the bandgap as seen experimentally through valence band XPS and optical data as well as theoretically through DFT calculations. The predicted values of the bandgaps of $\mathrm{BiOCl}, \mathrm{BiOBr}$ and $\mathrm{BiOI}$ are $c a$. 3.4, 2.8 and $2.0 \mathrm{eV}$, although it should be noted that these do not include thermal effects. Valence band X-ray photoemission spectra are shown in Fig. 7. To understand the orbital make-up of the valence band and further confirm that the correct material had been deposited, we have compared the XPS spectra to simulated XPS VB spectra calculated using the HSE06 functional with relativistic corrections (spin-orbit coupling). The simulated XPS VB spectra were obtained by scaling the calculated partial density of states using atomic orbital photoionisation cross-sections ${ }^{60}$ and broadened using a $0.47 \mathrm{eV}$ Gaussian function to simulate experimental broadening. The spectra are dominated by a broad valence band of $\mathrm{O} 2 \mathrm{p}$ states extending from the valence band onset to about $6-8 \mathrm{eV}$ binding energy, in excellent agreement with the calculated electronic structure. By simple linear extrapolation, the valence band edge for BiOI occurs at around $1.6 \mathrm{eV}$; for $\mathrm{BiOBr}$ occurs at around $2.2 \mathrm{eV}$ and for BiOCl occurs at around $2.9 \mathrm{eV}$. However, the absolute valence band edge positions cannot simply be derived by linear extrapolation of the rising edge of the valence band to 


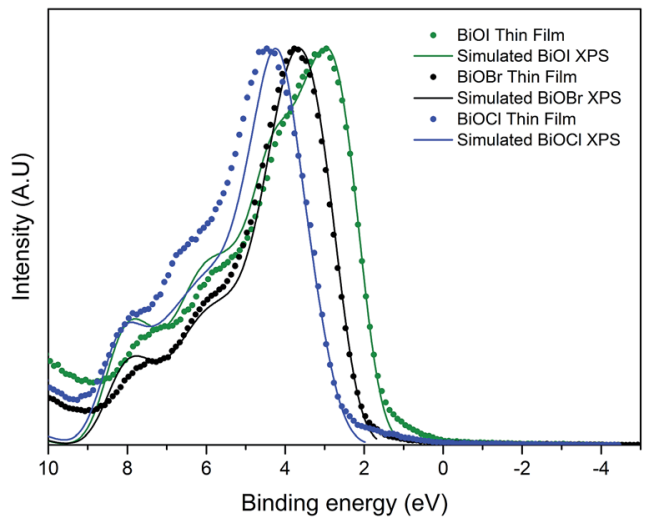

Fig. 7 Normalized valence-band photoemission spectra of the series of BiOX films prepared by AACVD, compared with HSEO6 + D3 + SOC simulated valence band XPS. Note the relative shift to a lower binding energy from $\mathrm{BiOCl}$ to $\mathrm{BiOl}$ showing band gap narrowing as you move down group 17 from $\mathrm{Cl}^{-}$to I-.

the baseline. According to the DFT calculations it has been shown that there is a rapid onset of the valence band density of states leading to an almost flat band. However, due to broadening of lifetime and instrument effects of the spectrometer, a significant slope to the measured onset of the valence band was seen. Therefore, extrapolating to the baseline results in a large underestimation in the VBM to surface Fermi level separation. The relative change in positions is in agreement with optical absorbance data.

\section{Photoelectrochemical testing}

Firstly, Mott-Schottky plots (impedance spectra) were recorded to investigate whether the as-synthesised materials exhibited nor p-type behaviour and to determine the flat-band potentials. From Fig. 8a, the M-S plot for BiOI displays n-type behaviour, due to the negative slope which, when extrapolated to the $x$-axis, yields a flat-band value of $-0.3 \mathrm{~V} v s . \mathrm{Ag} / \mathrm{AgCl}(+0.58 \mathrm{~V} v s$. RHE). Taking the typical difference between the conduction and flatband potentials to be $c a .0 .3 \mathrm{~V}$, the conduction band edge may be approximated to lie at $+0.3 \mathrm{~V} v$ s. RHE. $^{61}$ This is similar to the value reported by Mullins for spray-deposited BiOI films that also displayed n-type behaviour. ${ }^{51}$ Given that the measured indirect bandgaps of our BiOI films is $1.7 \mathrm{eV}$, the location of the valence band edge would correspond to $2 \mathrm{eV} v s$. RHE, indicating that the material could be utilised for photo-assisted water oxidation but not reduction. For AACVD-grown BiOCl films, the $\mathrm{M}-\mathrm{S}$ plot revealed p-type behaviour due to the negative direction of the slope as shown in Fig. 8b.

The flat-band position was calculated to be $2.15 \mathrm{~V} v s$. Ag/ $/ \mathrm{AgCl}$ ( $2.73 \mathrm{~V} v$ s. RHE), therefore the valence band position equates to roughly $2.43 \mathrm{~V} v s$. RHE, and given that the bandgap of our BiOCl is $3.2 \mathrm{eV}$, the CBE position is $-0.77 \mathrm{~V} v$ s. RHE. This suggests that $\mathrm{BiOCl}$ could be utilised as a potential photocathode for water splitting. The $\mathrm{M}-\mathrm{S}$ plot for the BiOBr film reveals n-type behaviour (Fig. 8c), with a flat-band potential of $-0.44 \mathrm{~V} v s$. $\mathrm{Ag} / \mathrm{AgCl}(0.14 \mathrm{~V} v s$. RHE), therefore a conduction band position of $-0.16 \mathrm{~V} v s$. RHE, in good agreement with previous reports. ${ }^{62} \mathrm{~A}$ valence band position of $2.44 \mathrm{~V}$ was calculated based on the bandgap value of $2.6 \mathrm{eV}$.

Therefore, we can construct a band diagram depicting the valence and conduction band positions of several bismuth oxyhalides with respect to the potentials of water splitting (at $\mathrm{pH}$ 0), see Fig. 9. Note the calculated CB minima for our AACVD grown BiOCl and BiOI film is more negative than the $\mathrm{H}_{2}$ evolution potential, this has been previously reported in the literature. ${ }^{62-64}$

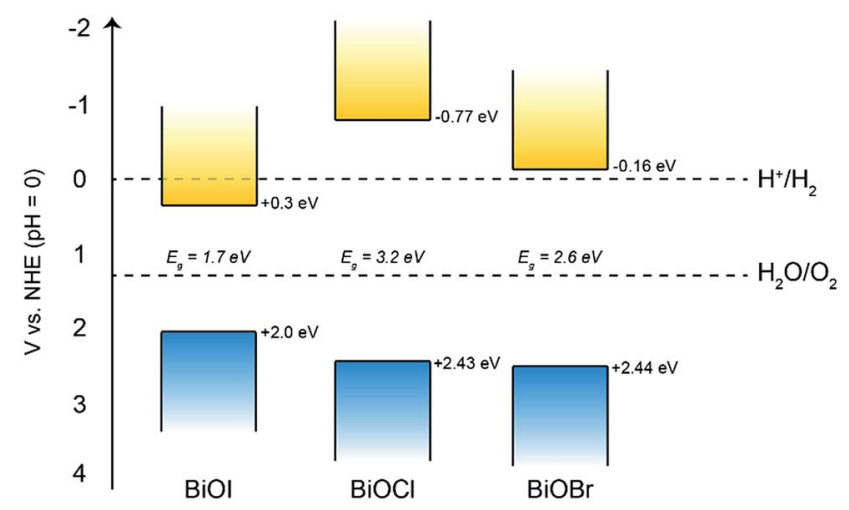

Fig. 9 The band positions of the bismuth oxyhalide films compared to the potentials of water splitting at $\mathrm{pH} 0$. Bandgap values of 1.7, 3.2 and $2.6 \mathrm{eV}$ were determined for the $\mathrm{BiOl}, \mathrm{BiOCl}$ and $\mathrm{BiOBr}$ films, respectively. a)

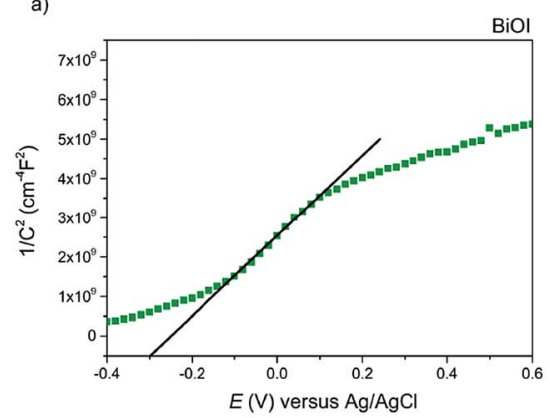

b)

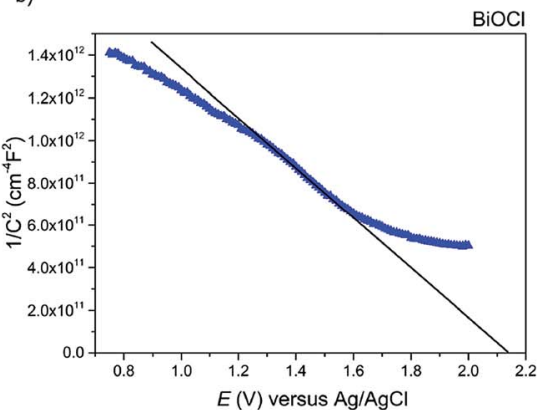

c)

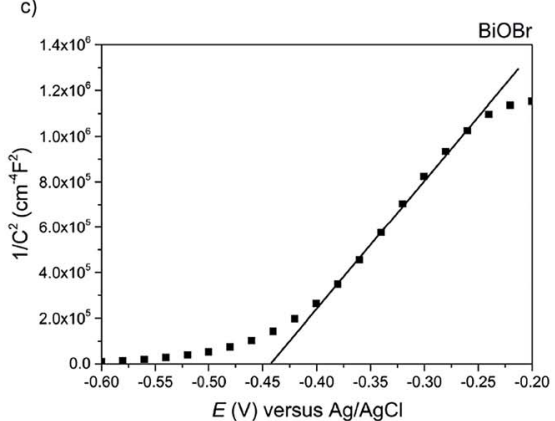

Fig. 8 The Mott-Schottky plot for the (a) BiOl, (b) BiOCl and (c) BiOBr films grown via AACVD. The BiOl and BiOBr films' $\mathrm{n}$-type behavior is apparent from the negative slope of the curve. The BiOCl film showed p-type properties. 
A recent review paper highlighted that bismuth oxyhalides exhibit appreciable activity for organic decomposition, however it was also mentioned that they have been rarely used for solar fuel processes, such as water splitting and $\mathrm{CO}_{2}$ photoreduction. ${ }^{65}$ To address this and to gain a fuller understanding of their photophysical properties, we tested the BiOX films synthesised via AACVD for photoelectrochemical properties under $100 \mathrm{~mW} \mathrm{~cm}{ }^{-2}$ illumination in $0.5 \mathrm{M} \mathrm{Na}_{2} \mathrm{SO}_{4}$ electrolyte. The current-voltage plot for the BiOCl film shows some photocathodic activity compared to the dark current, exhibiting a current of $c a .-1 \mathrm{~mA} \mathrm{~cm}^{-2}$ at $-0.4 \mathrm{~V}$ (vs. $\left.\mathrm{Ag} / \mathrm{AgCl}\right)$, however a very small anodic current was observed, approximately 0.1 $\mathrm{mA} \mathrm{cm}{ }^{-2}$ at $1.2 \mathrm{~V}$ (vs. $\left.\mathrm{Ag} / \mathrm{AgCl}\right)$ (see ESI $\dagger$ ). This is somewhat in agreement with the measured flat-band potential of the material, which suggested that it could show photocathodic activity. Furthermore, the applied bias-photon-to-current conversion efficiency (ABPE) was calculated to be $0.04 \%$. The stability test of the same film recorded at an applied voltage of $-0.4 \mathrm{~V} v s$. $\mathrm{Ag} / \mathrm{AgCl}$ is shown in the ESI. $\dagger$

Altogether the stability is relatively poor; the current actually increases then decreases, most probably due to photocorrosion. The cathodic photocurrent decreases by $25 \%$ after just 10 minutes of illumination. This clearly shows that BiOCl may be unsuitable for photocatalytic applications, particularly water splitting, in the absence of a protective coating. This issue is common for other photoactive materials such as $\mathrm{Cu}_{2} \mathrm{O}$, which requires typically $\mathrm{ALD}$ grown protective layers of $\mathrm{ZnO}$ and $\mathrm{Al}_{2} \mathrm{O}_{3}$ to help slow down corrosion in water during illumination. ${ }^{\mathbf{6 6}}$

The appearance of the BiOCl film after testing changed to black in colour, and photocorrosion to Bi metal species was confirmed via XRD analysis (not shown herein). Recently, the coupling of BiOCl with other metal oxides into a junction structure has resulted in improved performance for PEC water splitting; however in all such cases the performance of the bare BiOCl was either not reported or not addressed..$^{67,68}$ On the other hand, photocatalytic testing of $\mathrm{BiOBr}$ revealed good photoanodic activity, exhibiting a photocurrent of $c a .0 .38 \mathrm{~mA} \mathrm{~cm}^{-2}$ at $1 \mathrm{~V}$ vs. $\mathrm{Ag} / \mathrm{AgCl}$, see Fig. 10a. The ABPE of the BiOBr film was $0.25 \%$.

To the best of our knowledge, this is the highest photocurrent recorded for BiOBr electrodes without the use of a sacrificial electron donor. It is also over three times higher than that recorded for BiOBr-reduced graphene composite electrodes tested under similar conditions $\left(c a .75 \mu \mathrm{A} \mathrm{cm} \mathrm{cm}^{-2}\right.$ at $0.45 v s$. $\mathrm{Ag} / \mathrm{AgCl}){ }^{62}$ Improved photocurrent and photocatalytic activity has recently been reported for (001) oriented BiOBr samples for both organic contaminant decomposition and nitrogen fixation. ${ }^{63,69}$ In fact, we find that both the (001) and (101) facets are dominant in our samples as evidenced from XRD analysis, suggesting that at least a proportion of the improved photocatalytic activity is from charge transfer and separation along the (001) facet. The stability of the material was also tested at an applied potential of $1.0 \mathrm{~V}$ vs. $\mathrm{Ag} / \mathrm{AgCl}$ for 1 hour duration, revealing a $c a .23 \%$ decrease by the end of the experiment and no obvious change in appearance of the film (Fig. 10b). This test was for considerably longer than that reported previously in the literature. The slow photocorrosion of BiOBr is due to self- a)

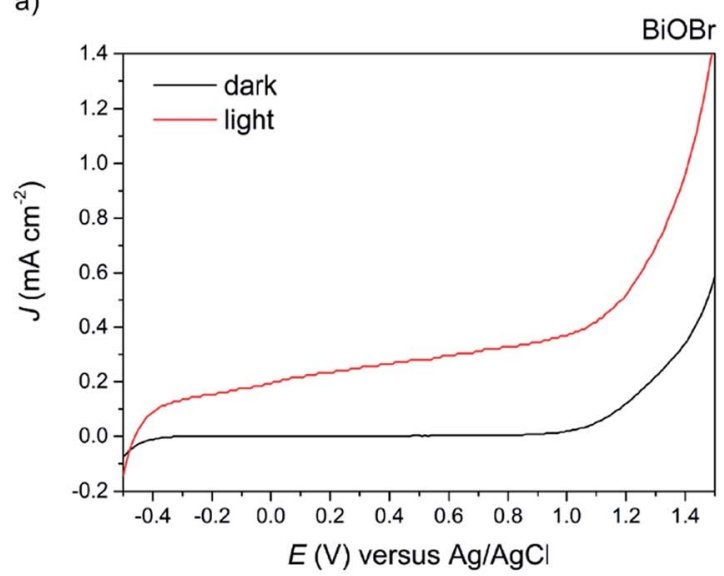

b)

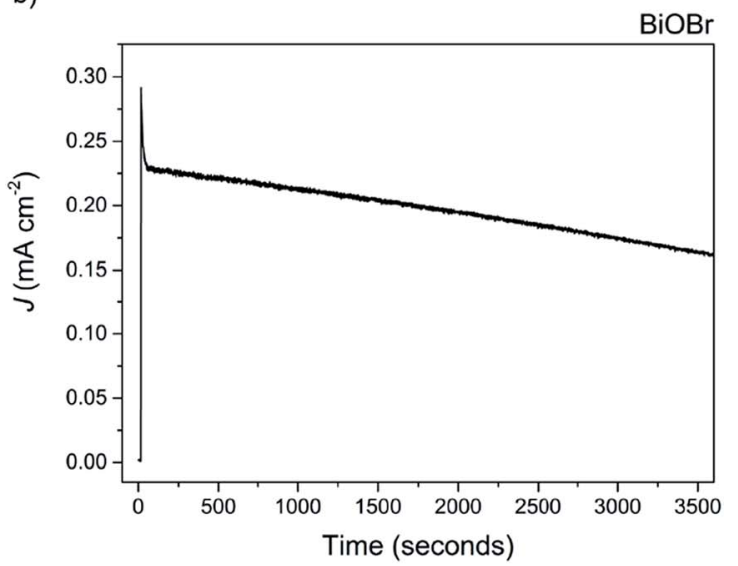

Fig. 10 (a) The current-voltage behavior of the AACVD grown $\mathrm{BiOBr}$ film under $100 \mathrm{~mW} \mathrm{~cm}{ }^{-2}$ illumination in $0.5 \mathrm{M} \mathrm{Na}_{2} \mathrm{SO}_{4}$ electrolyte. A photocurrent of ca. $0.38 \mathrm{~mA} \mathrm{~cm}^{-2}$ at $1 \mathrm{~V}$ vs. Ag/AgCl was observed. (b) The stability of the $\mathrm{BiOBr}$ film at an applied voltage of $1.0 \mathrm{Vvs}$. $\mathrm{Ag} / \mathrm{AgCl}$. There was a 23\% decrease after 1 hour.

reduction to Bi metal caused by photogenerated $\mathrm{CB}$ electrons; the application of an external bias does alleviate this by electron transfer to the counter electrode, although not $100 \%$ efficient. The complex mechanism of photocorrosion and electrode regeneration in these BiOX materials has already been discussed, ${ }^{70}$ but can be summarised as follows:

$$
\mathrm{BiOX}+2 \mathrm{H}^{+}+3 \mathrm{e}^{-} \rightarrow \mathrm{Bi}+\mathrm{X}^{-}+\mathrm{H}_{2} \mathrm{O}
$$

As our electrolyte was de-aerated, dissolved oxygen cannot act as an electron acceptor and therefore cannot protect BiOX as suggested in the above reference. Thus, we suggest a further option would be to add a passivation layer or to add a surface oxidation catalyst, which will separate surface electrons and holes and permit more efficient electron transfer to the counter electrode. ${ }^{13,71}$

Finally, BiOI synthesized via AACVD was tested for its PEC performance (Fig. 11a). To the best of our knowledge, this is the first report of the photoelectrochemical activity of BiOI. Anodic behaviour was observed, in agreement with the shape of the Mott-Schottky plot, with a maximum photocurrent of 0.15 
a)

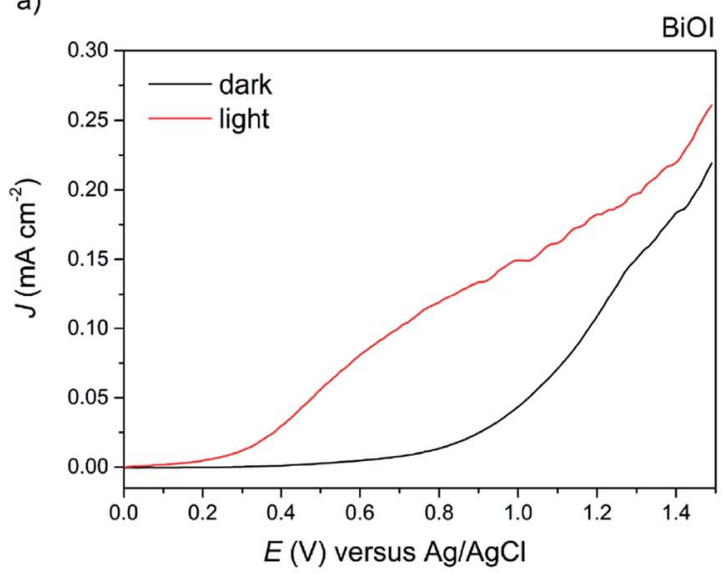

b)

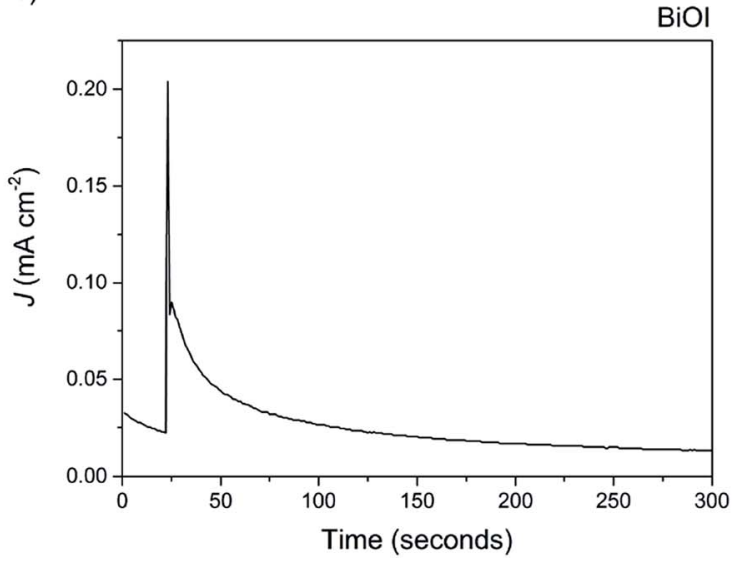

Fig. 11 (a) The current-voltage behavior of the AACVD grown BiOI film under $100 \mathrm{~mW} \mathrm{~cm}^{-2}$ illumination in $0.5 \mathrm{M} \mathrm{Na}_{2} \mathrm{SO}_{4}$ electrolyte. A photocurrent of ca. $0.15 \mathrm{~mA} \mathrm{~cm}^{-2}$ at $1 \mathrm{~V} v$ s. $\mathrm{Ag} / \mathrm{AgCl}$ was observed. (b) The stability of the $\mathrm{BiOBr}$ film at an applied voltage of $0.5 \mathrm{~V} v \mathrm{~s}$. $\mathrm{Ag} / \mathrm{AgCl}$. There was rapid decay after just 100 seconds.

$\mathrm{mA} \mathrm{cm}{ }^{-2}$ at $1 \mathrm{~V} v s . \mathrm{Ag} / \mathrm{AgCl}$ and an ABPE of $0.07 \%$. The dark current at this voltage was fairly high at $0.025 \mathrm{~mA} \mathrm{~cm} \mathrm{~cm}^{-2}$, indicative of the material's limited stability, particularly at higher applied potentials. To highlight this, a stability test was performed at an applied voltage of $0.5 \mathrm{~V} v s$. Ag/AgCl (Fig. 11b). To our surprise, BiOI exhibited an extremely rapid decay in photocurrent, and no photocurrent was observed after a period of just 100 seconds.

Overall, it was found that the stability of BiOBr is much superior to that of both BiOI and BiOCl under the present experimental conditions, which could have important implications for their future use in photo-assisted water splitting reactions. We suggest that the enhanced water oxidation property of BiOBr is mainly due to the very positive VB position, which possesses a higher overpotential for water oxidation compared to the other BiOX materials (Fig. 9). This is in addition to the dominant (001) facet in our AACVD grown BiOBr films which allows for improved charge separation. The poor stability of BiOI is of particular concern, whilst there are several reports of this material being used for degradation of organic dyes and pollutants, it cannot be used for water splitting reactions due to its facile photo-degradation.

These results should serve as a caution for those intending to utilise untreated bismuth oxyhalides for applications in photocatalytic systems. It may prove possible to enhance stability through morphological control. Otherwise, the use of co-catalysts or protection layers should be explored in order to extend the stability of these materials towards practical applications.

\section{Conclusion}

In conclusion, AACVD was used to grow a series of phase pure tetragonal matlockite structured $\operatorname{BiOX}(\mathrm{X}=\mathrm{Cl}, \mathrm{Br}, \mathrm{I})$ films at 300 ${ }^{\circ} \mathrm{C}$. SEM micrographs showed nanoplatelet morphology for $\mathrm{BiOCl}$ and BiOI whereas nanoflower like particles were observed for the BiOBr film. The optical bandgap calculations of the films agreed well with first-principles calculations that explained that the narrowing of the bandgap is due to the variation in the energy of the halide p orbitals that form the upper valence band. Functional testing showed that untreated BiOCl (p-type) and BiOI (n-type) were both unsuitable for photoelectrochemical applications as they showed poor stability. BiOBr revealed good photoanodic activity with a photocurrent of $c a .0 .38 \mathrm{~mA} \mathrm{~cm}{ }^{-2}$ at $1 \mathrm{~V} v$ s. $\mathrm{Ag} / \mathrm{Ag} \mathrm{Cl}$ - the highest photocurrent recorded for $\mathrm{BiOBr}$ electrodes without the use of a sacrificial electron donor. BiOBr also showed good stability, far better than BiOCl and BiOI under the testing conditions.

\section{Author contributions}

D. S. B. designed/carried out the experiments, performed the sample characterization measurements and analyzed the results. S. J. A. M. carried out the PEC measurements and analyzed the results. D. S. B., S. J. A. M., S. S., D. O. S. and A. W. wrote the manuscript. D. S. B., S. J. A. M., S. S. and A. W. made the figures. D. O. S. and A. W. performed and analyzed the computational measurements. C. J. C. and I. P. P. supervised D. S. B. and S. S. J. T. supervised S. J. A. M. D. O. S., A. W., I. P. P., J. T. and C. J. C. were involved in the design of experiments, editing of the manuscript and discussions throughout the work. S. M. B. was involved in a number of scientific discussions and analysis of results. A. Y. O. generated ideas and spearheaded the initial collaboration between the institutions. M. M. was involved with a number of scientific discussions and analysis of results and has provided valuable insights, which have in turn, directed the research. All authors contributed to the scientific discussion.

\section{Acknowledgements}

I. P. P. and C. J. C. acknowledge EPSRC for funding the work under Grant EP/L017709. D. S. B. acknowledges Mr Kevin Reeves for assistance with SEM. Thank you to Pilkington NSG for the glass substrates. This work made use of the ARCHER UK National Supercomputing Service (http://www.archer.ac.uk), via our membership of the UK's HEC Materials Chemistry Consortium, which is funded by EPSRC (EP/L000202), the Iridis 
cluster, provided by the EPSRC funded Centre for Innovation (Grant codes EP/K000144/1 and EP/K000136/1) and the UCL Legion HPC Facility (Legion@UCL). Thanks to Dr Ainara Garcia Gallastegui for useful discussions. S. S. acknowledges the Deanship of Scientific Research (DSR), King Abdulaziz University, Jeddah for funding the work under grant D-1-434. D. O. S. acknowledges EPSRC for funding the work under grant EP/ N01572X/1. The work at Bath was supported by the ERC (Grant no. 277757) and the EPSRC (Grant no. EP/K016288/1, EP/ L017792/1 and EP/M009580/1). S. M. and J. T. acknowledge funding from EU FP7 4G-PHOTOCAT Grant no. 309636.

\section{Notes and references}

1 A. H. Fujishima, K. Honda and S. Kikuchi, J. Chem. Soc. Jpn., 1969, 72, 108-113.

2 A. Fujishima and K. Honda, Nature, 1972, 238, 37-38.

3 A. J. Bard and M. A. Fox, Acc. Chem. Res., 1995, 28, 141-145.

4 M. G. Walter, E. L. Warren, J. R. McKone, S. W. Boettcher, Q. Mi, E. A. Santori and N. S. Lewis, Chem. Rev., 2010, 110, 6446-6473.

5 A. Kudo and Y. Miseki, Chem. Soc. Rev., 2009, 38, 253-278.

6 D. S. Bhachu, S. Sathasivam, G. Sankar, D. O. Scanlon, G. Cibin, C. J. Carmalt, I. P. Parkin, G. W. Watson, S. M. Bawaked, A. Y. Obaid, S. Al-Thabaiti and S. N. Basahel, Adv. Funct. Mater., 2014, 24, 5075-5085.

7 S. M. Bawaked, S. Sathasivam, D. S. Bhachu, N. Chadwick, A. Y. Obaid, S. Al-Thabaiti, S. N. Basahel, C. J. Carmalt and I. P. Parkin, J. Mater. Chem. A, 2014, 2, 12849-12856.

8 S. Sathasivam, D. S. Bhachu, Y. Lu, N. Chadwick, S. A. Althabaiti, A. O. Alyoubi, S. N. Basahel, C. J. Carmalt and I. P. Parkin, Sci. Rep., 2015, 5, 10952.

9 Z. Li, W. Luo, M. Zhang, J. Feng and Z. Zou, Energy Environ. Sci., 2013, 6, 347-370.

10 S. J. A. Moniz, S. A. Shevlin, D. J. Martin, Z.-X. Guo and J. Tang, Energy Environ. Sci., 2015, 8, 731-759.

11 S. Banerjee, S. C. Pillai, P. Falaras, K. E. O'Shea, J. A. Byrne and D. D. Dionysiou, J. Phys. Chem. Lett., 2014, 5, 2543-2554.

12 V. Etacheri, M. K. Seery, S. J. Hinder and S. C. Pillai, Chem. Mater., 2010, 22, 3843-3853.

$13 \mathrm{~S} . \mathrm{Hu}, \mathrm{M}$. R. Shaner, J. A. Beardslee, M. Lichterman, B. S. Brunschwig and N. S. Lewis, Science, 2014, 344, 10051009.

14 S. Kim, S.-J. Hwang and W. Choi, J. Phys. Chem. B, 2005, 109, 24260-24267.

15 R. Asahi, T. Morikawa, T. Ohwaki, K. Aoki and Y. Taga, Science, 2001, 293, 269-271.

16 T. Ihara, M. Miyoshi, M. Ando, S. Sugihara and Y. Iriyama, J. Mater. Sci., 2001, 36, 4201-4207.

17 S. Rehman, R. Ullah, A. M. Butt and N. D. Gohar, J. Hazard. Mater., 2009, 170, 560-569.

18 K. Maeda, T. Takata, M. Hara, N. Saito, Y. Inoue, H. Kobayashi and K. Domen, J. Am. Chem. Soc., 2005, 127, 8286-8287.

19 D. S. Bhachu, S. Sathasivam, C. J. Carmalt and I. P. Parkin, Langmuir, 2014, 30, 624-630.
20 J. Luo, J.-H. Im, M. T. Mayer, M. Schreier, M. K. Nazeeruddin, N.-G. Park, S. D. Tilley, H. J. Fan and M. Grätzel, Science, 2014, 345, 1593-1596.

21 I. Tsuji, H. Kato and A. Kudo, Angew. Chem., 2005, 117, 36313634.

22 Y. Zheng, J. Liu, J. Liang, M. Jaroniec and S. Z. Qiao, Energy Environ. Sci., 2012, 5, 6717-6731.

23 K. Maeda, X. Wang, Y. Nishihara, D. Lu, M. Antonietti and K. Domen, J. Phys. Chem. C, 2009, 113, 4940-4947.

24 X. Wang, K. Maeda, A. Thomas, K. Takanabe, G. Xin, J. M. Carlsson, K. Domen and M. Antonietti, Nat. Mater., 2009, 8, 76-80.

25 D. S. Su, J. Zhang, B. Frank, A. Thomas, X. Wang, J. Paraknowitsch and R. Schlögl, ChemSusChem, 2010, 3, 169-180.

26 J. Li, Y. Yu and L. Zhang, Nanoscale, 2014, 6, 8473-8488.

27 A. Huizhong, D. U. Yi, W. Tianmin, W. Cong, H. A. O. Weichang and J. Zhang, Rare Met., 2008, 27, 243250.

28 H. Zhang, L. Liu and Z. Zhou, Phys. Chem. Chem. Phys., 2012, 14, 1286-1292.

29 F. A. Bannister and M. H. Hey, Mineral. Mag., 1935, 24, 4958.

30 H. Peng, C. K. Chan, S. Meister, X. F. Zhang and Y. Cui, Chem. Mater., 2008, 21, 247-252.

31 J. Zhang, F. Shi, J. Lin, D. Chen, J. Gao, Z. Huang, X. Ding and C. Tang, Chem. Mater., 2008, 20, 2937-2941.

32 F. Yanfen, H. Yingping, Y. Jing, W. Pan and C. Genwei, Environ. Sci. Technol., 2011, 45, 1593-1600.

33 R. Yuan, S. Fan, H. Zhou, Z. Ding, S. Lin, Z. Li, Z. Zhang, C. Xu, L. Wu, X. Wang and X. Fu, Angew. Chem., Int. Ed., 2013, 52, 1035-1039.

34 N. Kijima, K. Matano, M. Saito, T. Oikawa, T. Konishi, H. Yasuda, T. Sato and Y. Yoshimura, Appl. Catal., A, 2001, 206, 237-244.

35 Z. Shan, W. Wang, X. Lin, H. Ding and F. Huang, J. Solid State Chem., 2008, 181, 1361-1366.

36 H. Cheng, B. Huang, Z. Wang, X. Qin, X. Zhang and Y. Dai, Chem.-Eur. J., 2011, 17, 8039-8043.

37 X. Zhang, Z. Ai, F. Jia and L. Zhang, J. Phys. Chem. C, 2008, 112, 747-753.

38 J. Chen, M. Guan, W. Cai, J. Guo, C. Xiao and G. Zhang, Phys. Chem. Chem. Phys., 2014, 16, 20909-20914.

39 Y. Mi, M. Zhou, L. Wen, H. Zhao and Y. Lei, Dalton Trans., 2014, 43, 9549-9556.

40 X. Tu, S. Luo, G. Chen and J. Li, Chem.-Eur. J., 2012, 18, 14359-14366.

41 G. Kresse and J. Hafner, Phys. Rev. B: Condens. Matter Mater. Phys., 1993, 47, 558.

42 G. Kresse and J. Hafner, Phys. Rev. B: Condens. Matter Mater. Phys., 1994, 49, 14251.

43 G. Kresse and J. Furthmüller, Phys. Rev. B: Condens. Matter Mater. Phys., 1996, 54, 11169.

44 G. Kresse and J. Furthmüller, Comput. Mater. Sci., 1996, 6, 15-50.

45 G. Kresse and D. Joubert, Phys. Rev. B: Condens. Matter Mater. Phys., 1999, 59, 1758. 
46 A. V. Krukau, O. A. Vydrov, A. F. Izmaylov and G. E. Scuseria, J. Chem. Phys., 2006, 125, 224106.

47 S. Grimme, J. Comput. Chem., 2004, 25, 1463-1473.

48 A. Ganose, C. N. Savory and D. O. Scanlon, J. Phys. Chem. Lett., 2015, 6, 4594-4598.

49 D. O. Scanlon, P. D. C. King, R. P. Singh, A. De La Torre, S. M. Walker, G. Balakrishnan, F. Baumberger and C. R. A. Catlow, Adv. Mater., 2012, 24, 2154-2158.

50 A. M. Ganose, C. N. Savory and D. O. Scanlon, J. Phys. Chem. Lett., 2015, 6, 4594-4598.

51 N. T. Hahn, S. Hoang, J. L. Self and C. B. Mullins, ACS Nano, 2012, 6, 7712-7722.

52 Z. Jiang, F. Yang, G. Yang, L. Kong, M. O. Jones, T. Xiao and P. P. Edwards, J. Photochem. Photobiol., A, 2010, 212, 8-13.

53 Y. Li, J. Wang, H. Yao, L. Dang and Z. Li, J. Mol. Catal. A: Chem., 2011, 334, 116-122.

54 L. Armelao, G. Bottaro, C. Maccato and E. Tondello, Dalton Trans., 2012, 41, 5480-5485.

55 V. S. Dharmadhikari, S. R. Sainkar, S. Badrinarayan and A. Goswami, J. Electron Spectrosc. Relat. Phenom., 1982, 25, 181-189.

56 D. S. Bhachu, D. O. Scanlon, E. J. Saban, H. Bronstein, I. P. Parkin, C. J. Carmalt and R. G. Palgrave, J. Mater. Chem. A, 2015, 3, 9071-9073.

57 R. Lindblad, D. Bi, B.-W. Park, J. Oscarsson, M. Gorgoi, H. Siegbahn, M. Odelius, E. M. J. Johansson and H. Rensmo, J. Phys. Chem. Lett., 2014, 5, 648-653.

58 Z. Ai, W. Ho, S. Lee and L. Zhang, Environ. Sci. Technol., 2009, 43, 4143-4150.
59 C. Chen, P. Hu, X. Hu, Y. Mei and Y. Huang, Chem. Commun., 2015, 51, 2798-2801.

60 J. J. Yeh and I. Lindau, At. Data Nucl. Data Tables, 1985, 32, 1155.

61 W.-J. Chun, A. Ishikawa, H. Fujisawa, T. Takata, J. N. Kondo, M. Hara, M. Kawai, Y. Matsumoto and K. Domen, J. Phys. Chem. B, 2003, 107, 1798-1803.

62 X. Tu, S. Luo, G. Chen and J. Li, Chem.-Eur. J., 2012, 18, 14359-14366.

63 H. Li, J. Shang, Z. Ai and L. Zhang, J. Am. Chem. Soc., 2015, 137, 6393-6399.

64 Y. Zhao, T. Yu, X. Tan, C. Xie and S. Wang, Dalton Trans., 2015, 44, 20475-20483.

65 L. Ye, Y. Su, X. Jin, H. Xie and C. Zhang, Environ. Sci.: Nano, 2014, 1, 90-112.

66 A. Paracchino, V. Laporte, K. Sivula, M. Grätzel and E. Thimsen, Nat. Mater., 2011, 10, 456-461.

67 W.-Q. Fan, X.-Q. Yu, S.-Y. Song, H.-Y. Bai, C. Zhang, D. Yan, C.-B. Liu, Q. Wang and W.-D. Shi, CrystEngComm, 2014, 16, 820-825.

68 W. Yang, B. Ma, W. Wang, Y. Wen, D. Zeng and B. Shan, Phys. Chem. Chem. Phys., 2013, 15, 19387-19394.

69 W. Lin, X. Wang, Y. Wang, J. Zhang, Z. Lin, B. Zhang and F. Huang, Chem. Commun., 2014, DOI: 10.1039/c3cc41498a.

70 S. K. Poznyak and A. I. Kulak, Electrochim. Acta, 1990, 35, 1941-1947.

71 C. Jiang, S. J. A. Moniz, M. Khraisheh and J. Tang, Chem.Eur. J., 2014, 20, 12954-12961. 